\title{
The "other" COPD
}

\author{
MeiLan K. Han
}

Affiliations: Division of Pulmonary and Critical Care, University of Michigan, Ann Arbor, MI, USA.

Correspondence: M.K. Han, Division of Pulmonary and Critical Care, University of Michigan, 1500 E Medical Center Drive, 3916 Taubman Center, Ann Arbor, MI 48109-0360, USA. E-mail: mrkingaumich.edu

@ERSpublications

Biomass smoke exposure may be more associated with an airway-predominant COPD phenotype than tobacco-related COPD http://ow.ly/qKuIu

Chronic obstructive pulmonary disease (COPD) is currently a leading cause of death worldwide, but the burden of disease shared by females is particularly heavy. In the USA alone, the number of deaths among females has quadrupled since 1980 and now exceeds male deaths from COPD; hospitalisation of females due to the disease also now surpasses that of males [1]. Concerns have also been raised that females may be more susceptible to the effects of tobacco smoke with respect to development of impaired lung function [2]. Other differences in symptom presentation and greater exacerbation frequency among females have also been noted $[3,4]$. However, when viewed globally, the impact of this disease in females is influenced not only by the burden of tobacco use but also the less discussed and less well studied COPD related to biomass smoke exposure. Biomass fuel in particular can be dangerous, as the fine particles derived from solid-fuel combustion can be breathed more deeply into the lungs [5]. It has been demonstrated that the indoor particulate concentrations resulting from biomass fuel combustion can be even higher than the outdoor particulate concentrations seen in even the most polluted cities [5]. Furthermore, the frequency and duration of contact with the polluted air also increases the risk of respiratory impairment. The widespread practice of using unprocessed biomass for cooking and space heating, often in unventilated housing, places females at even greater risk as cooking tends to be a female-predominant task.

While data regarding biomass smoke COPD is accumulating, how the phenotype of biomass smoke-related COPD compares to tobacco smoke-related COPD is not completely understood. MorAN-MENDOZA et al. [6] reported on a small cohort of females with wood smoke chronic bronchitis. $55 \%$ of the cohort demonstrated airflow obstruction, $69 \%$ demonstrated hyperinflation and $43 \%$ reduced diffusion capacity. Histological evaluation was available on 20 wood smoke exposed patients and compared to 20 tobacco smokers with chronic bronchitis. The degree of emphysema was similar and centrilobular in all cases. No difference was seen in prevalence or severity of bronchiectasis or pulmonary artery structural changes. RAMIREZ-VENEGAS et al. [7] examined a series of biomass smoke and tobacco smoke COPD patients from Mexico. The biomass group was primarily female, older, shorter and with greater body mass index (BMI) than the tobacco smoke group [7]. Airflow obstruction was more severe in smokers although quality of life and distance walked were similar. Mortality was also similar between groups when adjusted for forced expiratory volume in $1 \mathrm{~s}$ (FEV1), oxygen saturation, BMI and age.

In this issue of the European Respiratory Journal, CAMP et al. [8] describe, for the first time, significant phenotypic differences between COPD due to tobacco smoke and biomass smoke exposure in age- and FEV1-matched females. In this study, 21 female never-smokers with COPD and biomass exposure were compared with 22 female ex-cigarette smokers without biomass exposure. From a physiological standpoint, the degree of airflow obstruction, hyperinflation and air trapping were similar. However, the biomass group exhibited worse health status in several domains of the St George's Respiratory Questionnaire. In univariate analyses, emphysema on thoracic computed tomography assessed both visually and quantitatively for the biomass group was less, as was the size of emphysematous spaces. The radiologist's visual scores for air

Received: Sept 292013 | Accepted: Sept 302013

Conflict of interest: None declared.

Copyright (C)ES 2014 
trapping for the biomass exposed group were greater, as was a quantitative measure of air trapping, the inspiratory/expiratory mean lung density ratio (computed tomography lung density ratio). Visually scored bronchiectasis was also more common in the biomass smoke than in the tobacco smoke group, although no differences were seen in the quantitative metrics of the larger airways.

In multivariate analyses adjusted for age, lung function and height, the differences in emphysema severity between groups, size of emphysema spaces and visual scoring of air trapping all remained statistically significant. The finding that females in both groups had similar FEV1 \% pred but females with tobacco smoke COPD had more emphysema but less air trapping suggests that females with biomass smoke COPD may have more small-airway disease. Interestingly, in the report on wood smoke lung disease by MORANMeNDOZA et al. [6], a trend $(\mathrm{p}=0.056)$ was also seen in histologically identified bronchial inflammation, which was more common in wood smoke-exposed patients $(60 \%)$ than tobacco smokers $(25 \%)$.

A limitation of this analysis that must be recognised, however, is that there are significant ethnic differences between the biomass and tobacco smoke groups being compared. CAMP et al. [8] acknowledge that much of the biomass smoke exposure group lived in rural communities and were of indigenous descent, as opposed to the tobacco smoke exposure group born in urban communities who more often had Spanish ancestry. Height, for instance, was the only significant predictor of computed tomography lung density ratio in the multivariate model. Hence, it may be that height, as a surrogate for ethnicity, contributes to the observed phenotypic differences. Unfortunately, however, these are the realities of conducting such a study, and teasing out causality in such an observational study is difficult.

Another issue that is difficult to address is whether females exposed to biomass fuels are more susceptible to lung damage than males similarly exposed. It is known that females make up a greater percentage of neversmokers with COPD, suggesting a potential for greater susceptibility to second-hand smoke and pollutants $[1,9-11]$. These differences have been seen in urban and rural populations. An association between worse asthma control and various types of fuel used for cooking has been reported for females but not males in several studies conducted in different countries [12-14]. Together, these data suggest the risk of respiratory impairment for females exposed to biomass smoke may be greater than that for males.

Regardless, females still represent the majority of the exposed population and the present study highlights what an important public health problem this is. According to the World Health Organization, an estimated 3 billion people worldwide use coal or biomass fuels for cooking and heating. Biomass is a source of energy in $30 \%$ of urban and $90 \%$ of rural households in developing countries [15]. Wood alone still accounts for the majority of energy used in certain rural regions of Mexico [6]. Fortunately, simple solutions can be incredibly effective. For instance, one observational study showed that homes where people had undertaken simple ventilation measures had a lower incidence of COPD [16]. Given the high burden of disease attributable to biomass smoke exposure, more such studies will be needed not only regarding disease characterization but also prevention and treatment.

\section{References}

1 American Lung Association. Taking Her Breath Away: the Rise of COPD in Women. www.lung.org/lung-disease/ disparities-reports/rise-of-copd-in-women Date last accessed: September 27, 2013. Date last updated: June 2013.

2 Gan WQ, Man SF, Postma DS, et al. Female smokers beyond the perimenopausal period are at increased risk of chronic obstructive pulmonary disease: a systematic review and meta-analysis. Respir Res 2006; 7: 52.

3 Han MK, Postma D, Mannino DM, et al. Gender and chronic obstructive pulmonary disease: why it matters. Am J Respir Crit Care Med 2007; 176: 1179-1184.

4 Tashkin D, Celli B, Kesten S, et al. Effect of tiotropium in men and women with COPD: results of the 4-year UPLIFT trial. Respir Med 2010; 104: 1495-1504.

5 Varkey AB. Chronic obstructive pulmonary disease in women: exploring gender differences. Curr Opin Pulm Med 2004; 10: 98-103.

6 Moran-Mendoza O, Perez-Padilla JR, Salazar-Flores M, et al. Wood smoke-associated lung disease: a clinical, functional, radiological and pathological description. Int J Tuberc Lung Dis 2008; 12: 1092-1098.

7 Ramirez-Venegas A, Sansores RH, Perez-Padilla R, et al. Survival of patients with chronic obstructive pulmonary disease due to biomass smoke and tobacco. Am J Respir Crit Care Med 2006; 173: 393-397.

8 Camp PG, Ramirez-Venegas A, Sansores RH, et al. COPD phenotypes in biomass smoke- versus tobacco smokeexposed Mexican women. Eur Respir J 2014; 43: 725-734.

9 Lamprecht B, McBurnie MA, Vollmer WM, et al. COPD in never smokers: results from the population-based burden of obstructive lung disease study. Chest 2011; 139: 752-763.

10 Bridevaux PO, Probst-Hensch NM, Schindler C, et al. Prevalence of airflow obstruction in smokers and neversmokers in Switzerland. Eur Respir J 2010; 36: 1259-1269.

11 Miravitlles M, Ferrer M, Pont A, et al. Characteristics of a population of COPD patients identified from a population-based study. Focus on previous diagnosis and never smokers. Respir Med 2005; 99: 985-995.

12 Jarvis D, Chinn S, Luczynska C, et al. Association of respiratory symptoms and lung function in young adults with use of domestic gas appliances. Lancet 1996; 347: 426-431.

13 Mishra V. Effect of indoor air pollution from biomass combustion on prevalence of asthma in the elderly. Environ Health Perspect 2003; 111: 71-78. 
14 Agrawal S. Effect of indoor air pollution from biomass and solid fuel combustion on prevalence of self-reported asthma among adult men and women in India: findings from a nationwide large-scale cross-sectional survey. J Asthma 2012; 49: 355-365.

15 Bruce N, Perez-Padilla R, Albalak R. Indoor air pollution in developing countries: a major environmental and public health challenge. Bull World Health Organ 2000; 78: 1078-1092.

16 Diette GB, Accinelli RA, Balmes JR, et al. Obstructive lung disease and exposure to burning biomass fuel in the indoor environment. Glob Heart 2012; 7: 265-270. 